\title{
PERCEPTION OF INDIAN YOUTH ON DIGITAL ACTIVISM: MOTIVATION, BARRIERS AND RECOMMENDATIONS FOR EFFECTIVE UTILIZATION
}

\begin{abstract}
Kuhu Sharma
Young Leader for Active Citizenship, New Delhi, India Oakridge International School Mohali Punjab, India
\end{abstract}

Pranav Sangwan

Young Leader for Active Citizenship, New Delhi, India Dubai College, Dubai, UAE

\author{
Aniruddh Verma \\ Young Leader for Active Citizenship, New Delhi, India \\ Sanjay Ghodawat International School Kolhapur, \\ Maharashtra, India
}

Siya Kohli

Young Leader for Active Citizenship, New Delhi Delhi Public School, Navi Mumbai, Maharashtra

Tanvi Chakravarty

Young Leader for Active Citizenship, New Delhi, India BD Somani International School, Mumbai, Maharashtra

\begin{abstract}
The present study draws insights from primary research, examines the existing literature on the subject and uses case studies, with a prime objective to understand the use of social media by youth for digital activism. Thereafter, the paper provides recommendations for effectively leveraging digital platforms to encourage youth participation and activism. This research paper looks at the forms of Digital activism and the ways in which the youth have leveraged digital activism to voice their issues, highlighting their motivations and challenges. To get better insight into the barriers and motivations of youth participation in digital activism, multiple stakeholder conversations and survey of Indian youth within the age group 15-25 years (93 respondents) was conducted to gauge their perception on digital activism. Primary data was collected using an online survey from 93 respondents through a structured questionnaire. Results of this study showed that close to $76.09 \%$ of the sample does not engage in digital activism, despite $93.5 \%$ of them having a social media presence.
\end{abstract}

Key words: Social media, digital activism, Youth

\section{INTRODUCTION}

Over the past few decades, India has been recording a phenomenal rise in the number of active internet users in the country. With close to
624 million ${ }^{1}$ active internet users (as of January 2021 ) - the country recorded a whopping $11,200 \%$ increase from the 2000 numbers ${ }^{2}$. This large database of audience can be leveraged and mobilized with ease, thereby giving rise to 'Digital Activism', which has, over the years, gained prominence as a recognized form of activism. Digital Activism essentially refers to the use of online tools to raise awareness and bring change on various social and political fronts. Digital activism is a form of activism wherein digital means (internet \& smartphones) and tools (social media, blogs etc.) are used as a conduit to inform, engage, mobilize, fund and/or bring change in various social, political, environmental and other causes $^{3}$. Digital activism is increasingly the preferred mode of activism because it provides a platform for expression to anyone with access to digital media. This is especially beneficial to represent diverse perspective countering dominant narratives and challenge the status quo of existing social norms. Digital activism not only allows citizens to drive change but also helps give the general public a better understanding of what is going on and can put pressure on governments to take action on issues that are not normally reported in the conventional media ${ }^{4}$. Today, social media not only provide a resource for political or social discussion, but also create opportunities to discuss and transmit information, thereby encouraging collective action. Social media are central to contemporary social activism as advanced tools of communication and 
information. Beyond simply sending and receiving messages, social media facilitate collective action, reduce cost and time, and overcome the cognitive constraints of individuals ${ }^{5}$. Social media mobilize and recruit individuals for collective action efforts on contentious issues ${ }^{6,7}$. More important, they make it easier for users to express personal opinions and to organize collective activities. Keeping in mind above facts, present study was undertaken with following objectives:

\section{Objective:}

The major objective of the study was: 1. to understand how Digital Activism can be made more effective for youth, 2. To know the use, forms and need of Digital activism by Indian youth, and 3. To find the ways in which the youth have leveraged digital activism to voice their issues, highlighting their motivations and barriers.

\section{REVIEW OF LITERATURE}

\section{A. Forms of digital activism}

As per Sandor $\mathrm{Vegh}^{8}$, Digital activism can take many forms but can be broadly divided into three categories:

\section{Awareness raising/Advocacy activism:}

The internet allows individuals and organizations to disseminate information which may not be reported, underreported or misreported by mainstream media. Digital activism allows users to shed light on these issues, build communities through solidarity, or put pressure and demand action and accountability from authorities. For example, The Queer Muslim Project, an Instagram community, counters queerphobia and Muslim hate through representation of individual stories, and creates opportunities for selfrepresentation ${ }^{9}$.

2. Mobilization / Organization activism: Digital activism can be an effective way to organize or call for offline action. It can also be used to call for demonstrations or highlight issues to the concerned authorities, governmental or private, through email or other social media platforms ${ }^{10}$. During the second wave of the COVID-19 pandemic in April 2021, several individuals came together to form groups on social media such as the Covid Resources India ${ }^{11}$ and Covid Care Goa groups $^{12}$, which used digital tools like Instagram and Whatsapp to amplify verified calls for oxygen, ICU beds, medicines and mobilize volunteers to assist those in need of help.

3. Active/Reactive activism: Under this category, activists use hacking as a form of civil disobedience to promote political agenda or social change. However, this form of activism often creates problem as a result of its malicious and destructive nature as it undermines the security of the internet. Anonymous, an internationally decentralized group of hacktivists, took down child porn sites $^{13}$ which experts fear could have put the ongoing police investigations at risk.

Digital activism is most successful when used as a complementary tool to physical activism by either encouraging or organizing offline action like strikes, peaceful protests, marches, etc. It is generally a non-violent form of activism. Malicious hacking and cyber terrorism are the exceptions that form only a small part (2-3\%) of digital activism ${ }^{4}$.

\section{B. Need for Digital Activism}

Individuals living in today's networked society have entered a new phase in problem solving on contentious issues. Individuals in the social media environment not only are easily exposed to social issues, but also engage in the issues by creating and transmitting information ${ }^{14}$.

Digital Activism has an edge over other forms of activism due to several reasons. Apart from being cost-efficient and a low-effort tool, it can easily be used to raise awareness and provide diverse experience to counter dominant narratives ${ }^{4}$. Before the advent of social media, broadcasting a message was relatively expensive and only the big organizations or government agencies could afford to run campaigns and mobilize large crowds. The advent of social media has created a platform that can easily amplify people's voice. As a result, online activism began creating a transformational impact on the society. Online petitions are gathering momentum - freerodneyreed.com is an example of an online petition that gathered over two million signatures. Even social media campaigns, such as those of \#ALSicebucketchallenge (to raise awareness on ALS) and Movember (to raise awareness on men's health issues) that have gone viral on the internet, have been an effective means to raise funds ${ }^{10}$.

Especially during the pandemic, Digital Activism emerged as a means to bring a change when the physical modes of activism were difficult to carry out $^{15}$. By bringing together the online community, this form of activism creates a space for people to exchange and share views on various social issues. This also allows individuals to become more active participants, which in-turn encourages them to explore more traditional forms of activism ${ }^{10}$.

\section{METHODOLOGY}

The paper uses reviews of the existing literature on the subject, case studies and draws insights from primary data collection to inform the research. A stakeholder consultation was 


\section{International Journal of Engineering Applied Sciences and Technology, 2021 \\ Vol. 6, Issue 4, ISSN No. 2455-2143, Pages 233-238 \\ Published Online August 2021 in IJEAST (http://www.ijeast.com)}

organized to have an in-depth understanding of motivations and barriers of utilizing social media for digital activism by Indian youth. The stakeholders were senior officials/ campaigner/activists from youth organizations/ NGOs. Thereafter, the paper provides recommendations for effectively leveraging digital platforms to encourage youth participation and activism. These recommendations are based on survey responses, stakeholder consultation findings, and findings from the secondary research.

For primary data collection, Indian youth within the age group 15-25 years (93 respondents) were surveyed online to gauge their perception on digital activism. The online survey was conducted from June 20 to July 01, 2021. Participants in the age group 15-25 were sent the online survey link. A survey questionnaire was created on Google forms, which contained objective of survey and a questionnaire. This study attempted to examine how individuals engage in collective action in the social media environment, and their participatory behaviors on social issues.

\section{RESULTS}

The total sample size for data analysis was 93, with $45.16 \%(n=42)$ male respondents and $53.76 \%(n=50)$ female respondents and other comprised $1.08 \%$. The majority of respondents $(63.04 \%)$ were in the age group $15-8$ years (Table $1)$.

Table 1: Use of Social Media by Respondents

\begin{tabular}{|c|c|c|c|}
\hline S.No & Parameter & $\mathbf{n}$ & $\%$ \\
\hline \multirow[t]{4}{*}{1} & Age Range & & \\
\hline & $15-18$ & 58 & 63.04 \\
\hline & $19-21$ & 9 & 9.78 \\
\hline & $22-25$ & 25 & 27.17 \\
\hline \multirow[t]{4}{*}{2} & Gender & & \\
\hline & Male & 42 & 45.16 \\
\hline & Female & 50 & 53.76 \\
\hline & Other & 1 & 1.08 \\
\hline \multirow[t]{3}{*}{3} & $\begin{array}{l}\text { Having Social } \\
\text { Media Account }\end{array}$ & & \\
\hline & Yes & 87 & 93.55 \\
\hline & No & 6 & 6.45 \\
\hline \multirow[t]{5}{*}{4} & $\begin{array}{l}\text { Number of digital } \\
\text { platforms } \\
\text { respondents are } \\
\text { active on }\end{array}$ & & \\
\hline & $1-2$ & 28 & 30.11 \\
\hline & $3-5$ & 50 & 53.76 \\
\hline & $6-8$ & 10 & 10.75 \\
\hline & $8+$ & 5 & 5.38 \\
\hline 5 & $\begin{array}{l}\text { Use of account for } \\
\text { any forms of } \\
\text { political or }\end{array}$ & & \\
\hline
\end{tabular}

\begin{tabular}{|c|c|c|c|}
\hline & $\begin{array}{l}\text { apolitical activism } \\
\text { by respondents }\end{array}$ & & \\
\hline & Yes & 22 & 23.91 \\
\hline & No & 70 & 76.09 \\
\hline \multirow[t]{7}{*}{6} & $\begin{array}{l}\text { Respondents view } \\
\text { if using social } \\
\text { media for } \\
\text { activism is } \\
\text { effective }\end{array}$ & & \\
\hline & Yes & 51 & 56.67 \\
\hline & No & 14 & 15.56 \\
\hline & Sometime & 11 & 12.22 \\
\hline & May be & 6 & 6.67 \\
\hline & To some extent & 5 & 5.56 \\
\hline & Often & 3 & 3.32 \\
\hline \multirow[t]{7}{*}{7} & $\begin{array}{l}\text { Top six social } \\
\text { media used by } \\
\text { youth }\end{array}$ & & \\
\hline & Instagram & 79 & 84.95 \\
\hline & Youtube & 73 & 78.49 \\
\hline & Snapchat & 50 & 53.76 \\
\hline & Facebook & 35 & 37.63 \\
\hline & Twitter & 33 & 35.48 \\
\hline & LinkedIn & 30 & 32.26 \\
\hline
\end{tabular}

A big percentage of respondents $(93.5 \%)$ were having social media account. Majority of respondents were using 3-5 social medias, 30\% respondents were using only 1-2 social media while a small percentage $(5 \%)$ were using eight or more social media. When asked further to know the social media platforms commonly used by surveyed youth, Instagram $(84.9 \%)$ topped the list followed by Youtube (78.5\%), Snapchat (50\%), Facebook (37.6\%), Twitter $(35.5 \%)$ and Linkedin $(32.3 \%)$. When asked if respondents use the social media account for any forms of political or apolitical activism by majority of the respondents (76.09\%) replied no and less than one forth $(23.91 \%)$ replied that they used it for some kind of activism. When Respondents were asked to give their views if using social media for activism is effective, more than half $(56.67 \%)$ felt that yes it has an effect, while $15.57 \%$ felt that it does not have any impact and is not effective, a small percentage $(6.67 \%)$ felt that it some times may affect and $12.22 \%$ felt that it may be effective (Table 1). Respondents were asked to rate the effectiveness of digital activism on a scale of 1 to 10 , where 1 indicated not at all and 10reflected extremely effective $8.6 \%$ respondents felt that it is not effective at all, a small percentage felt that it is extremely effective (fig 1). 


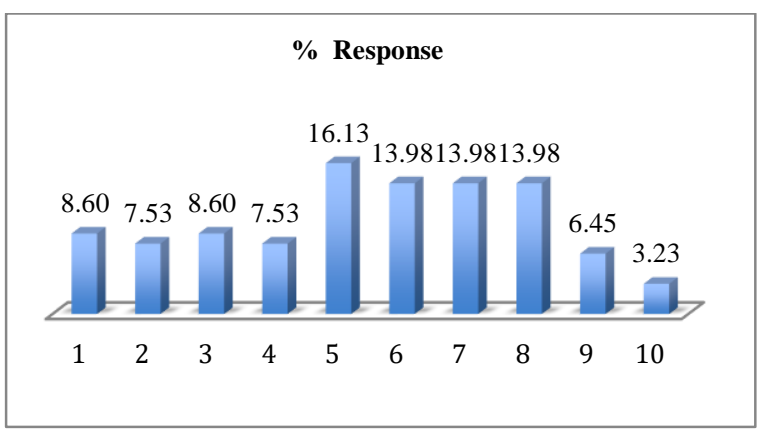

Fig 1: Youth opinion on effectiveness of digital activism been in influencing change in their daily life on a scale of 1-10 where 1 indicates- Not at all and 10 indicates Extremely Effective

\section{DISCUSSION}

Motivations for Indian youth: This section attempts to provide insights into the possible reasons behind a large disparity between social media presence and engagement in digital activism amongst the Indian youth.

The study produced some major findings. From current research, it was found that the youth (1525 years) has grown up with technology and has a thorough understanding of social media, thus making them the most apt at using technology for activism. Some of the reasons that encourage youth to participate in digital activism are:

\section{Accessible communities for shared interests}

Digital activism allows for creation of communities mobilizing youth based on their shared interests. These communities, often become safe spaces and provide its members with encouragement and support for individua growth and development. For example, the Artidote ha become a successful community on Facebook an Instagram of passionate advocates for mental wellbeing.

\section{Raising awareness on underrepresented experiences}

Activists have often used social media as a tool to shed light change. on underrepresented personal experiences. For example, Aastha Shah, a 23-year-old influencer from Mumbai uses her Instagram page to raise awareness about vitiligo and encourage body positivity.

\section{RECOMMENDATIONS FOR EFFECTIVE LEVERAGING DIGITAL PLATFORMS FOR ACTIVISM}

\section{Channel for individual expression} Especially in the wake of the COVID-19 pandemic, digitaleffective and a developed tool for activism, there activism has allowed the youth to share their experiences is still a lack of youth civic engagement due to and perspective on issues which are important to them.barriers stemming from the unregulated nature of These platforms also allow diverse means of expression likedigital platforms. To overcome these obstacles, the art, photography, short videos or blogs. Using digital tools following are some recommendations that can for sharing personal narratives and deriving support fromhelp encourage youth participation and promote online communities has largely helped many young peopleeffective digital activism:

gain confidence in voicing their concerns.

1. Digital Education and Empowerment: To tackle the lack of digital awareness and 
education that acts as a barrier to youth participation in digital activism, there is a need to create easily consumable content on digital literacy and work with influencers to promote them. Additionally, collaborating with schools to reach a wider audience can also be useful. Promoting content that highlights issues faced by Dalits and women can help empower marginalized sections of the society who do not have 'internet privilege'. To increase digital accessibility to these groups, there is a need to reach out to the community representatives of rural areas - including the local heads - and work with them to develop digital literacy campaigns, web series, posters, etc. and make them more accessible in their community.

2. Encouraging more active civic engagement: There is a need to actively involve the youth in digital activism by offering them summer internships, recruiting young assistants, actors, directors, etc. to lay emphasis on the need for activism rather than 'slacktivism'. Furthermore, creating a communication channel for open political/apolitical discourse that make netizens feel like they have safe space to engage in digital activism can go a long way in encouraging youth participation.

3. Need for Personal, accessible and consistent activism: To encourage greater internet mobilisation, there is a need for more personal, accessible and consistent activism. Majority of our survey respondents used keywords such as 'creative', 'relatable', 'informative' content when suggesting the type of tactics that online activists should use to raise awareness about social issues. Examples of incorporating these suggestions include but are not limited to the following:

- Developing content with real life stories (anonymous if necessary) to develop a deeper connection with the audience, which can help build trust and increase credibility.

- Conducting online courses and awareness campaigns to equip users to while consuming information as news and building the mindset to promote factcheck and promote news on social media.

- Having a fact checking series, competitions or campaigns on Instagram, Twitter, Facebook, etc. to reduce misinformation and enhance the trust in digital platforms. This could be done through infographics or fact checking social media posts. Further, having awareness campaigns can help the users develop an aptitude to question facts and information for themselves before promoting it on social media. This can go a long way in mitigating spread of misinformation and fake news.

\section{CONCLUSION}

Digital activism has seen an exponential rise in the last few decades and has transformed and evolved to become an effective medium of mass mobilisation, advocacy and a tool for raising awareness. While forms of digital activism such as petitions, hashtag activism and twitter storms have been successful in bringing systemic change, it is clear that the most effective role of digital activism in the future would be in the form of a supplement to the offline conventional activism rather than a substitute. In evaluating the effectiveness of digital activism, we found limitations such as digital divide, digital amnesia, 'slacktivism' as well as other barriers like censorship that may stem the potential impact of digital activism. However, these issues can be addressed by enhancing youth participation, increasing digital literacy through awareness campaigns and providing access to digital platforms in rural areas. Overall, despite a few shortcomings, the decentralized nature of digital activism makes it an effective tool that the youth can leverage to voice their opinions and participate in civic engagement.

\section{ACKNOWLEDGEMENT}

The study is part of project of Young Researchers for Social Impact (YRSI) Program conducted by Young Leaders for Active Citizenship (YLAC). This study was undertaken as part of the June 2021 edition of the program.

\section{REFERENCES}

(1) S. Kemp, "Digital in India: All the Statistics You Need in 2021" DataReportal - Global Digital Insights, available at www.datareportal.com/reports/digital, 2021.

(2) Internet World Stats. "Internet Top 20 Countries - Internet World Users." Internetworldstats.Com, www.internetworldstats.com/top20.htm. Accessed 21 June 2021.

(3) M. Fuentes, "Digital Activism." Encyclopedia Britannica, www.britannica.com/topic/digitalactivism. Accessed 28 June 2021.

(4) A. Rees , "Digital and Online Activism" eds |Responsibility." RESET.To, en.reset.org/knowledge/digital-and-onlineactivism. 2020 . Accessed 28 June 2021. 
(5) B. Bimber, A. J. Flanagin, C. Stohl, "Reconceptualizing collective action in the contemporary media environment", Communication Theory, 15, 365-388, 2005.

(6) W.L. Bennett \& Segerberg, A. The logic of connective action: Digital media and the personalization of contentious politics.

Information, Communication \& Society, 15, 739$768,2012$.

(7) W.L.Bennett \& A. Segerberg, The logic of connective action: Digital media and the personalization of contentious politics. Cambridge, UK: Cambridge University Press, 2013.

(8) V. Sandor, Classifying Forms of Online Activism: The Case of Cyber protests against the World Bank in Cyber activism, Routledge eds $1,2003$.

(9) The Queer Muslim Project: available at https://www.instagram.com/thequeermuslimprojec t/ Accessed on 3 July 2021.

(10) M. Mccaughey, M.D. Ayers eds "Cyberactivism - Online Activism in Theory and Practice" Newyork Routledge, 2004.

(11) Covid Aid Resources: available at https://www.instagram.com/covidaidresources

(12) Covid Care Goa, available at https://www.instagram.com/covidcaregoa.in
13. BBC News, "Hackers take down child pornography sites". Available at www.bbc.com accessed on 20 June 2021

(14) M.Chon, P.H. Hyojung, "Social Media Activism in the Digital Age: Testing an Integrative Model of Activism on Contentious Issues" 97,1, 72-97, 2020

(15) J. Pinckney "Amid Coronavirus, Online Activism Confronts Digital Authoritarianism". United States Institute of Peace, 2020.

(16) D. Dumitricia and M. Felt "Mediated Grassroots Collective Action: Negotiating Barriers of Digital Activism", Information, Communication \& Society, 23:13, 18211837,DOI: $\underline{10.1080 / 1369118 X .2019 .1618891}$, 2019. 